DOI 10.37882/2223-2974.2020.11.37

\title{
ОСОБЕННОСТИ ПЕРЕХОДА ОТ ТРАДИЦИОННОЙ ЭКОНОМИКИ К ЭКОНОМИКЕ УСТОЙЧИВОГО РАЗВИТИЯ В УСЛОВИЯХ ГОСУДАРСТВЕННОГО ЧАСТНОГО ПАРТНЕРСТВА
}

\section{FEATURES OF THE TRANSITION FROM THE TRADITIONAL ECONOMY TO THE ECONOMY OF SUSTAINABLE DEVELOPMENT IN A PUBLIC PRIVATE PARTNERSHIP}

\section{O. Chibisov}

E. Chibisova

Summary: In the context of the importance of global using the process of innovation in the conditions of public private partnership, natural resource restrictions, the institutions of the traditional economy are relevant for the economy of sustainable development, the same traditions are the main form of human wealth. In our view, sustainable development is possible only by balancing the market and government regulation. The market is not always equilibrium and functions effectively, it is not always possible to provide a socially acceptable distribution of benefits, so government intervention today must be seen as an inevitable, necessary buffer tool to stabilize and correct the negative effects of the market.

Keywords: economic development, economy, legal support, sustainable development, generational acceptability, degradation of resources.

\section{Чибисов Олег Валерьевич}

К.э.н., доцент, Российская государственная академия интеллектуальной собственности (РГАИС)

79250504296@ya.ru

Чибисова Елена Ивановна

К.э.н., дочент, Российская государственная академия интеллектуальной собственности (РГАИС); Московский автомобильно-дорожный государственный технический

университет (МАДИ)

Аннотация: В условиях значимости глобальных используя процесс инновационной деятельности в условиях государственного частного партнерства, природно-ресурсных ограничений, институты традиционной экономики актуальны для экономики устойчивого развития, сами же традиции является основной формой человеческого богатства. На наш взгляд добиться устойчивого развития возможно исключительно путем балансирования между рынком и государственным регулированием. Рынок не всегда находится в равновесии и функционирует эффективно, не всегда может обеспечить социально приемлемое распределение благ, поэтому государственное вмешательство сегодня необходимо рассматривать как неизбежный, необходимый инструмент-буфер для стабилизации и исправления негативных последствий рынка.

Ключевые слова: экономическое развитие, экономика, правовое обеспечение, устойчивое развитие, приемлемость поколений, деградация ресурсов. $\ni$ кономика устойчивого развития берет свои истоки от традиционной системы, разница в том, что устойчивое развитие предусматривает стремительный экономический рост и технический прогресс, в отличие от традиционной экономики, сфера деятельности которой в натуральном хозяйстве, заключается в том, что экономика устойчивого развития затрагивает все сферы деятельности с минимальным вредом окружающей среде [2].

Устойчивая экономика - это процесс эффективного развития, направленного на изменения, связанные с чередованием использование природных ресурсов, и привлечение инвестиций, а также развитие личности и институциональные изменения. населения. Которые не возможны без участия государства в роли частного партнера.

Создание уникальных конкурентных преимуществ в условиях обостряющейся конкуренции на мировом рынке становится для отечественных предприятий всё более актуальным [4]. Опыт передовых экономик показывает, что создание таких преимуществ напрямую зависит от возможности реализации в стране инновационной деятельности со стороны государства и поддержка отечественной экономики государством на правах частного партнёрства. Под инновационной, в данном случае, понимается деятельность (включая научную, технологическую, организационную, финансовую и коммерческую), направленная на реализацию инновационных проектов, а также на создание инновационной инфраструктуры и обеспечение её функционирования при поддержке как на законодательном так и на финансовом уровне со стороны государства [6].

Задачами государственного управления в сфере интеллектуальной собственности на современном этапе общественного развития в России являются реализация результатов интеллектуальной деятельности в массовом производстве, а также в различных сферах деятельности; гармонизация системы отношений между ведущими субъектами сферы интеллектуальной собственности (государством, бизнесом и автором) в интересах развития национальной инновационной экономики [8, с. 112].

Государственная политика в области интеллектуаль- 
ной собственности заключается в совершенствовании имеющихся возможностей, создании механизмов их реализации в системе конкретных мер по повышению конкурентоспособности отечественного производства, без которого российское производство не может быть конкурентным на международном уровне [10, с. 517].

В современных условиях реализация инновационных проектов уже не может быть полностью связана с бюджетным финансированием, возможности которого в последнее время резко сократились, что во многом зависит от привлечения к таким проектам бизнеса и от его спроса на инновационные разработки, а также зависимость бюджета от продажи нефти и газа [12, с. 280]. В сложившихся условиях государство вынуждено искать новые пути привлечения дополнительных финансовых ресурсов в бюджет и не только за счет увеличения налогового бремени, таким выходом из сложившейся ситуации не сменно может стать ГЧП как возможность поддержки отечественных производителей и получения стабильного дохода в ввиду части прибыли в зависимости от участия, а также это возможность реализовать наиболее значимые, но менее доходные социальные проекты [14, с. 37].

B XXI веке прирост производительности труда и ВВП в развитых странах обеспечивается в основном за счет выпуска и реализации наукоёмкой продукции и услуг. Инновационный процесс из «точечного» экономического явления постепенно превратился в доминанту экономического развития [16, с. 368].

Востребованность инновационного пути развития отечественной экономики стала более ясной с наступлением кризиса 2013-2018 года, когда возникли проблемы на традиционном для России сырьевом рынке.

На мировом рынке наукоёмкой продукции удельный вес принадлежит США - 36-40 \%, Японии - около $30 \%$, Германии - $16 \%$, Китаю - 6 \%, России - 0,3-0,5 \%. К сожалению, в России лишь 8 \% роста ВВП достигается за счет инновационного сектора.

Сегодня доля инновационно-активных предприятий по России составляет 8,5 \%, а для 100 крупных (с годовым оборотом свыше 100 млн. долл.) компаний этот показатель равен $39 \%$. Необходимость же государственночастного партнерства в инновационной сфере вызвана тем, что сама инновационная деятельность не является предпринимательской в чистом виде [20].

Можно отметить важнейшую роль ГЧП:

- механизм создания добавочной стоимости (доля ИС может достигать 10-15\% от цены реализуемой продукции);

- средство капитализации активов предприятий и организаций (через нематериальные активы и участие государства);

- как инвестиционный ресурс (где под залог ИС предоставляются кредиты, займы и банковские гарантии).

Также одной из основных проблем является отсутствие универсальных специалистов-посредников, являющихся профессиональными участниками такого рынка, в компетенцию которых будут входить вопросы стратегии формирования и коммерциализации ИС, способы и формы правовой охраны и последующей защиты ИС, стратегии в отношении персонала [22, с. 535]. В данном случае роль и поддержка государства очевидна так как оно может создавать дополнительные бюджетные места для таких специалистов с гарантией и обязательным их трудоустройством на предприятия и проекты в которых государство выступает в роли частного партера [1].

Усиления роли ИС в экономике можно определить по формуле

$$
\text { РИС }=г С+4 И, \text { где (1) }
$$

РИС - уровень усиление интеллектуальной собственности в экономике;

ГС - Государственный ресурс;

чП - частная инициатива.

Необходимым и обязательным условием успеха в развитии экономики ИС выступает эффективное государственное регулирование, которое предполагает следующие направления деятельности в этой сфере:

- централизованная по горизонтали и вертикали система государственного администрирования процессами в целях снижения барьеров развития использования результатами интеллектуальной деятельности (РИД);

- система учета НИОКТР и распределения исключительных прав на РИД, полученных при бюджетном финансировании;

- система индикаторов и показателей оценки результативности науки и выполнения государственных контрактов;

- управление правами государства на РИД;

- государственное стимулирование и обеспечение инновационной активности за счет соблюдения баланса интересов «автор-заказчик- исполнитель» при бюджетировании НИОКТР.

Государство должно выступать во- первых в роли гаранта, во вторых принять на себя часть риска, особенно на первых стадиях любого проекта или частного партнерства, что делает такое участие государства наиболее значимым и более эффективным и дает определенные гарантии участникам проектов [3]. 
В утвержденной 17 ноября 2008 года распоряжением Правительства Российской Федерации No1662-р Концепции долгосрочного социально экономического развития РФ на период до 2020 года указано, что одним из стратегических направлений такого развития является государственно-частное партнерство в инновационной сфере. Которое не было реализованы в полном объеме поставленные задачи. Так среднегодовой рост ВВП в 2014-2018 годах составил лишь 0,5\%. При запланированном 6,5\%, а в 2019-2020 годах рост, согласно прогнозу Минэкономразвития, составил 1,3- 1,7\%. Что так же ниже прогнозируемого результата.

Ускорение экономики ожидается только с 2021 года, до 3,1-3,3\%, но при условии реализации обширной программ связанных с улучшения делового климата, снижения административных барьеров для бизнеса, цифровизации экономики, по нашему мнению такой подъем может быть реализован также за счет программы государственного частного партнерства [5].

К 2020 году по сравнению с 2012 годом реальный ВВП должен был вырасти на 64-66\%, следовало из разработанной концепции. Но фактическая динамика ВВП с 2012 года, дает другие результаты в 2013-2019 годах он вырос только на 5,8\%.

К сожалению, в это период наблюдалась тенденция снижения роста доходов населения с 2012 года к 2019 года фактические располагаемые доходы населения России сократились примерно более чем на 5\%. Такая же тенденция наблюдалась и в среднем классе к концу 2019 началу 2020 года к нему можно отнести не более 38\% россиян, что тоже имеет тенденцию к снижению по сравнению с периодами до 2010г. При этом полностью соответствуют всем критериям среднего класса лишь 10,3 млн. человек, или 7,5\% по всей стране [7, с. 30]. Однако по подсчетам ведущих финансистов Альфа- Банка также наблюдается тенденция к снижению, но по их расчетам доля среднего класса в России составляет в среднем 30\% населения приблизительно 45 млн. человек.

Средний уровень обеспеченности жильем к 2020 году должен был достигнуть 28-35 кв. м на человека (или около 100 кв. м на среднестатистическую семью). Однако по данным Росстата, в среднем на одного человека приходится 25,8 кв. м жилья.

Концепция также предусматривала перераспределение бюджетной средств в зависимости от уровней бюджета в пользу расходов на развитие человеческого потенциала - с 8,6\% от ВВП в 2020 году. В частности, расходы на здравоохранение должны были увеличиться с 3,6\% ВПП до 5-5,5\%, на образование - с 4 до 5-6\% ВВП [18].
В настоящее время в Российской Федерации в качестве сторон государственно- частного партнёрства в реализации инновационной деятельности выступают [9, с. 222]:

- государство, в лице органов государственной власти различного уровня.

- частный партнёр, к ним можно отнести юридических и физических лиц, осуществляющих свою деятельность на основе рыночной экономики с целью извлечения прибыли;

- научные организация, предназначенные для разработки инновации, в лице является высшее учебное заведение, НИИ и лабораторий.

Можно выделить с точки зрения мировой практики признаки государственно- частного партнёрства [11]:

- равные права участников и партнёров;

- обязательное наличие договорных отношений для снижения рисков, регламентирующих взаимоотношения партнёров;

- наличие чётко определённых интересов государства, которые формулируются до подписания партнёрского договора;

- определение у участников, точно обозначенных целей, задач, и уровня участия;

- распределение рисков прибылей и убытков в зависимости от доли и уровня участия.

В разработанном Министерством экономического развития Российской Федерации проекте федерального закона № 238827-6 «Об основах государственно- частного партнёрства в Российской Федерации» было установлено, что государственно-частное партнёрство - «это взаимодействие публичного партнёра (органа представляющего интересы государства), с одной стороны, и частного партнёра, с другой стороны, осуществляемое на основании заключённого по результатам конкурсных процедур соглашения о государственно-частном партнёрстве, направленное на повышение качества и обеспечение доступности предоставляемых услуг населению, а также на привлечение в экономику частных инвестиций, стороны соглашения принимают на себя оговоренные в нём обязательства» [13].

Реализация проектов будет касаться не только инновационной сферы, но и социальной и образовательной (потребность в новых кадрах, специалистах, программах дополнительного профессионального образования, повышения квалификации и профессиональной переподготовки), и сферы регионального развития субъектов Российской Федерации на основе приоритетных местных экономических интересов, что будет содействовать снижению бюджетной зависимости от экспорта энергоносителей, политике импортозамещения и решению других актуальных задач в сфере экономики. 
Большинство международных организаций, входящих в ООН, включило в свою деятельность существенную экологическую составляющую, которая ориентирована на переход к устойчивому развитию.

Концепция устойчивого развития, представляет собой баланс интересов поколений.

Концепция устойчивого развития возникает как новая парадигма глобальной социальной жизни человека, способная стать направляющим вектором глобального перехода цивилизации к новым форматам развития.

Для устойчивого развития необходим рост. По версии Всемирного банка, главными показателями устойчивости являются как «истинные нормы инвестиций в стране», так и «истинные темпы сбережений». Таким образом, можно сказать, что устойчивое развитие экономики России невозможно без соблюдений требований мировых сообществ.

Данная концепция возникла в результате объединения экономической, социальной и экологической точек зрения. Экономический подход основан на теории максимального потока совокупного дохода, автором которого является Линдаля Хикс- Линдаль, Суть концепции - оптимальное использовании всех видов ресурсов, природо-, материало-, энергосберегающих технологий, создание экологически чистой продукции, снижение затрат, активное уничтожение и переработка отходов.

Социальную составляющую, ориентирована на человека и на поддержание стабильности культурных и социальных систем, уменьшение разрушительных конфликтов между гражданами. Основой этой составляющей является справедливое разделение существующих благ.

Культурная составляющая или культурный капитал, использует практику устойчивого развития, которая существует в не доминирующих культурах, то есть современное общество должно проводить политику эффективных решений, которая учитывает исторический мировой опыт и опыт, и историю конкретного государства являющейся основой межпоколенной справедливости, поскольку человек является субъектом развития, а не его объектом.

Мероприятия по устойчивому развитию экономики направлены на расширение участие человека в процессах, которые создают его жизнедеятельность, способствовать приятию решения, контролировать их выполнение.

С точки зрения экологии устойчивое развитие должно обеспечить целостность физических и биологиче- ских природных систем. Наибольшее значение имеет работа экосистем - от этого зависит глобальная стабильность всей нашей биосферы. Переход к устойчивому развитию дает возможность постепенно восстановить естественные экосистемы до такого уровня, который бы гарантировал стабильность окружающей среды, что возможно можно достичь усилиями всего человечества, но начинать движение к данной цели каждая страна должна самостоятельно.

Устойчивое социальное развитие: повышение уровня доходов, воспроизводство человеческих ресурсов.

Особое значение приобретает управление интеллектуальной собственностью в условиях неопределенности и рисков при создании системы устойчивого развития и государственного частного партнерства.

Соглашение о ГЧП должно содержать условие о передаче одной сторон или обеими сторонами результатов интеллектуальной деятельности средств индивидуализации, необходимых для исполнения соглашения.

Объект государственно-частного партнёрства изначально находится в государственной или муниципальной собственности и передаётся в собственность частному партнёру на срок, ограниченный началом эксплуатационной стадии, срок действия договора или без ограничения срока. ГЧП в сфере интеллектуальной собственности представляет собой передачу права использования (исключительного права) в отношении объектов интеллектуальной собственности публичным образованием или государственным учреждением частному лицу.

Варианты данных ГЧП могут быть классифицированы в зависимости от прав частного инвестора на объекты интеллектуальной собственности.

В ходе реализации ГЧП может происходить развитие практико- ориентированных научных направлений, формирование мест практики для студентов университетов, создание новых результатов интеллектуальной деятельности.

Вариантом ГЧП также выступает создание совместных предприятий под инновационный проект. Государственный и частный партнёр объединяют свои усилия, принимая взаимную ответственность за внедрение и реализацию инновации. При этом создаётся новая компания или разделяется право собственности на уже существующую компанию. Происходит передача исключительного права на результат интеллектуальной деятельности частному лицу - вновь созданной или реорганизованной компании. Данное лицо использует интеллектуальную собственность по усмотрению соз- 
давших его сторон ГЧП, в связи с чем возникает задача согласования интересов государственного и частного партнёров.

Государственный и частный партнёр могут иметь различные интересы по коммерциализации интеллектуальной собственности. В то же время, при правильном распределении ролей партнёрство обеспечивает максимальные возможности для реализации интересов всех участников взаимодействия вследствие объединения ресурсов.

Для эффективного развития государственно-частного партнерства в инновационной сфере необходимо, кроме четкой спецификации прав собственности на результаты интеллектуальной деятельности, обеспечение ее действенной защиты.

1. Юридическая защита прав частной собственности.
2. Четкая спецификация прав собственности, особенно в сфере интеллектуальной собственности.

3. Разработка системы законодательных и подзаконных актов, регулирующих отношения в сфере интеллектуальной собственности.

4. Государственная политика, устанавливающая прозрачные «правила игры» применительно к мелкой, средней и крупной частной собственности.

5. Меры по легитимации крупной частной собственности, что должно повысить возможности собственника.

Также необходима разработка долгосрочной государственной стратегии в области интеллектуальной собственности, что позволит осуществить системный подход к выработке государственной политики в сфере интеллектуальной собственности.

\section{ЛИТЕРАТУРА}

1. Федеральный закон от 23 августа 1996 г. № 127-Ф3 «0 науке и государственной научно-технической политике» // Собрании законодательства Российской Федерации. 1996. № 35. от 26 августа. ст. 4137.

2. Федеральный закон № 22428.09.2012 года «06 инновационном центре «Сколково».

3. Федеральный закон от 13.07 .15 Ф3-224 «0 государственно-частном партнерстве».

4. Утверждённая 17 ноября 2008 года распоряжением Правительства Российской Федерации №1662-р Концепции долгосрочного социально экономического развития РФ на период до 2020 года указано, что одним из стратегических направлений такого развития является государственно-частное партнёрство в инновационной сфере. Однако, в настоящее время данная концепция не дало ожидаемых результатов, поскольку на первом этапе до 2012 года предполагалось создание базовых нормативных документов и начало их реализации. Однако в 2008 году из-за глобального финансового кризиса цели концепции во многом стали нереализуемыми уже на старте;

5. Министерство экономического развития Российской Федерации проекте федерального закона № 238827-6 «06 основах государственно-частного партнёрства в Российской Федерации»;

6. Распоряжение Правительства РФ от 07.06.2006 N 838-р (ред. от 11.11.2006) «06 утверждении сводного плана мероприятий по реализации основных положений Послания Президента Российской Федерации Федеральному Собранию Российской Федерации 2006 года» // Собрание законодательства РФ.2006. № 25. от 19 июня. ст. 2747.;

7. Андрианова В.Д. Эволюция основных концепций регулирования экономики от теории меркантилизма до теории саморегуляции. // Экономика, 2008. С. 326. Глазьев, С.Ю. Управление развитием, фактор устойчивого экономического роста // Проблемы теории и практики управления 2010 . № 4.

8. Бобина И.С., Чибисов 0.В. Индикаторы социальной составляющей устойчивого развития на национальном уровне. Альманах мировой науки. 2019. № 1 (27).

9. В поисках нового метода изучения экономической мысли Чибисова Е.И. Историко-экономические исследования. 2017. Т. 18. № 1.

10. Голубев Г.Н., Данилов-Данильян В.И. Еще раз об основе устойчивого развития природы и общества // Вестник РАН. 2014. Т. 65 . № 6.

11. Громова Е.А. Государственно-частное партнерство в цифровую эру: поиск оптимальной правовой формы. Государственно-частное партнерство в цифровую эру: поиск оптимальной правовой формы // сайт https://urfac.ru/?p=1125.

12. Интервенционизм в экономике. Российский кейс недавней экономической истории. Чибисова Е.И., Чибисов О.В., Попов Г.Г. Российское предпринимательств0. 2016. Т. 17. № 3.

13. Коптюг В.А. Конференция ООН по окружающей среде и развитию (Рио- де-Жанейро, 1992 г.) // Информационный обзор. Новосибирск: СО РАН, 1992.

14. Кузнецова Е. - Стратегическая концепция устойчивого развития экономики // Проблемы теории и практики управления. 2007.№3.

15. Нуреев Р.М. Экономическая теория курс микроэкономики // Традиционная экономика 2016.

16. Овчинников Г.П., Яковлева Е.Б. Макроэкономика // Бизнес-Пресса, 2012.

17. Панфилова Т.В. Ценности глобализированного мира: общечеловеческие или обесчеловеченные? // Философия и 0бщество 02/2014.

18. РБK: https://www.rbc.ru/economics.

19. Чибисова Е.И., Попов Г.Г. Интервенционизм в экономике. Российский кейс недавней экономической истории Российское предпринимательство Том 17 , Номер 3 (Февраль 2016). 
20. Чибисова Е.И., Чибисов О.В. Научные исследования. 2018: теоретическая часть: монография. Раздел 5. Теоретические исследования в области культурологии 100 «Формирования, сохранения и использования интеллектуального капитала России» Год издания: 2018 ISBN 978-5-6040971-1-3 Издатель: Р.A. СОВА Категория: монографии Область наук: Многопрофильные издания.

21. Oleg Valeryevich Chibisov, Elena Ivanovna Chibisova Improvement of Corporate Operations in Inventory Management International Journal of Applied Business and Economic Research ISSN: 0972-7302 available at http: www.serialsjournal.com, Serials Publications Pvt. Ltd. Volume 15 Number 82017.

22. Online payments market from the global and russian viewpoint: the main problems and perspectives of e- commerse Bondarenko T.G., Soltakhanov A.U., Chibisova E.I., Chibisov 0.V. В сборнике: 5th International Multidisciplinary Scientific Conference on social sciences and arts SGEM 2018 Conference proceedings. 2018.

\section{( ) Чибисов Олег Валерьевич (79250504296@уа.ru), Чибисова Елена Ивановна. \\ Журнал «Современная наука: актуальные проблемы теории и практики»}

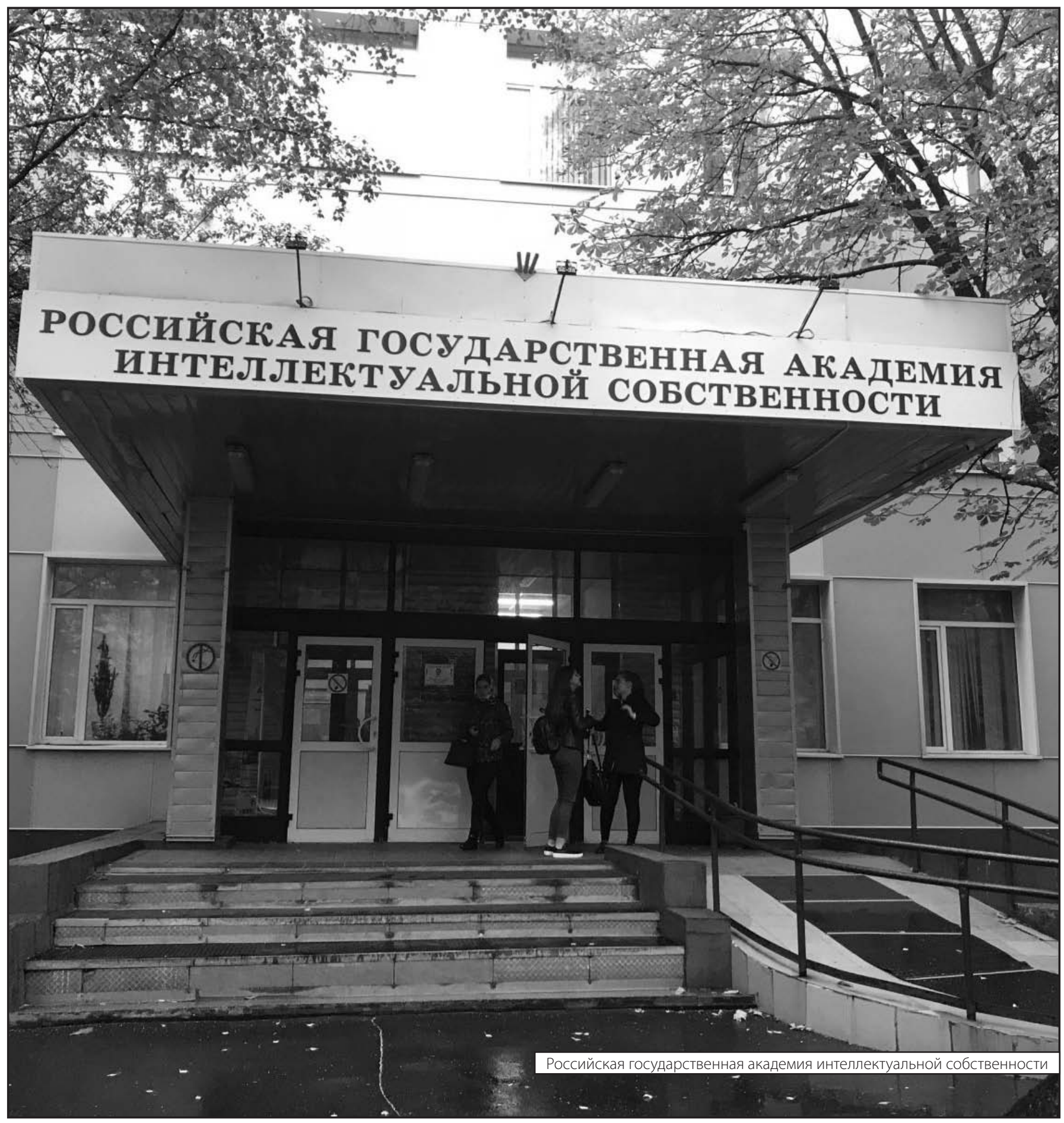

